\title{
Efectos del entrenamiento en velocidad de procesamiento sobre el sistema atencional en personas mayores: resultados preliminares
}

\author{
A. Buján, L. Lorenzo-López, J. Blanco-Fandiño, A. Maseda, I. González-Abraldes, J.C. \\ Millán-Calenti \\ Universidade da Coruña, Grupo de Investigación en Gerontología, Instituto de Investigación Biomédica de A \\ Coruña (INIBIC), Complexo Hospitalario Universitario de A Coruña (CHUAC), SERGAS, A Coruña
}

Objetivos: El entrenamiento regular de la velocidad de procesamiento (EVP) ha demostrado efecto beneficioso en tareas proximales, especialmente en actividades de atención selectiva. El objetivo de este trabajo es presentar resultados preliminares sobre eficacia del EVP sobre las tres redes atencionales de alerta, orientación y control ejecutivo en personas mayores.

Métodos: Diez participantes fueron aleatorizados en dos grupos: grupo experimental, EVP durante 3 meses $(n=5$; media de edad $=70 \pm 4,3 ; \operatorname{MoCA}=25,2 \pm 1,8)$; grupo control: realizó juegos de ordenador $(\mathrm{n}=5$; media de edad $=71 \pm 4,8$; MoCA: $26,8 \pm 1,8)$ durante el mismo periodo de tiempo. Las medidas de resultado fueron los tiempos de reacción (TR) obtenidos ante una tarea de atención, consistente en responder hacia donde apuntaba una flecha central, en dos condiciones diferentes (congruente versus incongruente), precedidas o no de una pista (doble pista, pista espacial). Se analizaron el tipo de pista y el tipo de estímulo diana mediante ANOVA de medidas repetidas.

Resultados: Los TR disminuyeron a medida que el tipo de pista era más informativo (pista espacial = $493 \mathrm{~ms}$; doble pista $=585 \mathrm{~ms}$; sin pista $=606 \mathrm{~ms})$, y también para los ensayos congruentes $(520 \mathrm{~ms})$ con respecto a los incongruentes $(603 \mathrm{~ms})$. Para ambos ANOVA, tanto en función del tipo de pista como del tipo de estímulo, se encontraron efectos significativos para el factor tiempo, interacción tiempo×grupo, e interacción tiempoxcondición (tipo de pista, o tipo de estímulo), revelando que los TR fueron significativamente menores en ambos grupos y para todas las condiciones estudiadas tras 3 meses de intervención.

Conclusiones: A la vista de estos resultados preliminares podemos concluir que no parece existir una ventaja del entrenamiento en velocidad de procesamiento sobre el uso regular de juegos de ordenador, al menos en lo que respecta a la mejoría de la función atencional. Por otro lado, ambos tipos de entrenamiento parecen tener un efecto positivo sobre la velocidad de procesamiento, reduciendo los TR generales ante los tres tipos de redes atencionales. 